\title{
POLÍTICAS DE EDUCAÇÃO CORPORATIVA E O PROCESSO DE CERTIFICAÇÃO BANCÁRIA: DISTINTOS ATORES E PERSPECTIVAS
}

\author{
Wilson Aparecido Costa de Amorim* \\ wamorim@usp.br
}

Marcus Vinicius Gonçalves da Cruz**

marcus.cruz@fjp.mg.gov.br

Amyra Moyzes Sarsur***

asarsur@hotmail.com

\author{
André Luiz Fischer* \\ afischer@usp.br \\ *Universidade de São Paulo - São Paulo, SP / Brasil \\ **Fundação João Pinheiro - Belo Horizonte, MG / Brasil \\ ***Fundação Pedro Leopoldo - Pedro Leopoldo, MG / Brasil
}

http://dx.doi.org/10.1590/1413-2311.0012015.54926

Recebido em 04/02/2015

Aprovado em 21/12/2015

Disponibilizado em 31/12/2015

Avaliado pelo sistema "double blind review"

Revista Eletrônica de Administração

Editor: Luís Felipe Nascimento

ISSN 1413-2311 (versão "on line")

Editada pela Escola de Administração da Universidade Federal do Rio Grande do Sul.

Periodicidade: Quadrimestral

Sistema requerido: Adobe Acrobat Reader

\section{RESUMO}

As iniciativas de educação corporativa vêm se institucionalizando como elemento de competitividade entre países (LANVIN; EVANS, 2013), organizações (EBOLI et al. 2010) e indivíduos (SARSUR, 2010). Como parte do resultado da melhor estruturação da educação corporativa, a qualificação da mão de obra traz no seu bojo os processos de certificação profissional. Neste contexto, o sistema financeiro brasileiro revela instituições mais efetivas na intermediação financeira e na geração de resultados, lastreadas em ações de educação corporativa e políticas de gestão de pessoas. O presente artigo delineia esta perspectiva analisando o movimento de certificação de trabalhadores bancários no Brasil, sob a égide de atores distintos como o órgão regulador; os bancos e suas universidades corporativas; as certificadoras; os sindicatos e os bancários. Verificaram-se por meio de pesquisa qualitativa de cunho descritivo, utilizando-se como instrumentos de coleta de dados a análise documental, entrevistas e grupo de foco, as políticas de gestão de pessoas sob o escopo da educação corporativa e o processo de certificação bancária sob a perspectiva destes atores. Os principais achados indicam que o Banco Central do Brasil normatiza o mercado, os bancos induzem ao processo de certificação bancária como mecanismo de ampliação de 
Wilson Aparecido Costa de Amorim, Marcus Vinicius Gonçalves da Cruz, Amyra Moyzes Sarsur \& André Luiz Fischer

competitividade e pressão sobre o indivíduo enquanto trabalhador, e por sua vez os sindicatos atuam como coadjuvantes no processo.

Palavras-Chave: educação corporativa; certificação bancária; gestão por competências, Banco Central do Brasil, sindicato, bancos.

\title{
CORPORATE EDUCATION INITIATIVES AND THE PROCESS OF BANK CERTIFICATION: DISTINCT ACTORS AND PERSPECTIVES
}

\begin{abstract}
The corporate education initiatives have been institutionalized as an element of competitiveness between countries (LANVIN; EVANS, 2013), organizations (EBOLI et al 2010.) and work force (SARSUR, 2010). This article outlines this approach by analyzing the labor certification of bank workers in Brazil, under the auspices of various actors as the regulatory body; banks and their corporate universities; certifiers; and unions. It was conducted a qualitative research describing Human Resources Management policies reviewing corporate education and the process of bank certification. It is concluded that the Brazilian Central Bank regulates the market, banks induce labor certification process as a competitiveness broadening mechanism and pressure on the labor workers, and the unions act as adjuvant in the process.
\end{abstract}

Keywords: corporate education; bank certification; competency management; Brazilian Central Bank; union; banks.

\section{RESUMEN}

\section{POLÍTICAS DE EDUCACIÓN CORPORATIVA Y EL PROCESO DE}

\section{CERTIFICACIÓN DE BANCO: DIFERENTES ACTORES Y PERSPECTIVAS}

Las iniciativas de educación corporativa se han institucionalizado como un elemento de competitividad entre países (LANVIN; Evans, 2013), las organizaciones (EBOLI et al 2010.) y personas (Sarsur, 2010). Este artículo describe esta perspectiva el análisis del movimiento de certificación de trabajadores bancarios en Brasil, bajo la égida de los diferentes actores como el regulador; bancos y sus universidades corporativas; certificadores; los sindicatos y la banca. Al comprobar a través de la investigación descriptiva políticas de gestión de personas de naturaleza cualitativa bajo el alcance de la educación empresarial y el proceso de certificación del banco, se concluyó que el Banco Central de Brasil regula el mercado, los bancos inducen proceso de certificación bancaria como mecanismo de competitividad y la presión de la ampliación en el individuo, y los sindicatos actúan como auxiliares en el proceso.

Palabras Clave: educación corporativa; certificación bancaria; gestión por competencias; Banco Central de Brasil, unión, bancos. 


\section{INTRODUÇÃO}

Os processos relacionados ao desenvolvimento dos países têm na educação de modo geral, e na educação corporativa em particular, um dos seus elementos de competitividade fundamentais (LANVIN; EVANS, 2013), uma vez que incentivam a manutenção de talentos nas organizações, impulsionam o desenvolvimento individual e fortalecem as dinâmicas de internacionalização do mercado de trabalho. Como parte do resultado da melhor estruturação da educação corporativa, a qualificação da mão de obra traz no seu bojo os processos de certificação profissional. No Brasil, o processo de certificação para fins escolares e profissionais foi impulsionado pelo aumento dos parâmetros de escolarização da população a partir da década de 1990. Também atuaram, neste sentido, políticas de qualidade e produtividade exigidas por um novo ordenamento da economia global e, consequentemente, as mudanças técnico-organizacionais que afetam as relações de trabalho (MORAES; LOPES NETO, 2005). Eboli (2004, p.92) salienta que o cenário competitivo dos anos 2000 forçou algumas instituições financeiras a desenvolverem e implantarem suas estratégias de diferenciação a partir da adoção de conceitos de gestão de pessoas por competências, "contemplando a implantação de um sistema integrado e estratégico de educação corporativa." O crescimento das iniciativas de educação corporativa no ramo financeiro, coincidentes com a implantação de processos de certificação laboral dentre seus trabalhadores, revelam tal opção como parte de seu leque estratégico para o crescimento e desenvolvimento das organizações do setor.

Em um cenário em que a gestão por competências se consolida como área de conhecimento e de prática de gestão de pessoas nas organizações (BARBOSA; BITENCOURT, 2010), o sistema financeiro brasileiro revela instituições mais efetivas na intermediação financeira e na geração de resultados. Os bancos no Brasil vêm respondendo dinamicamente ao contexto de estabilidade monetária, preservando elevados níveis de rentabilidade (BACEN, 2013). Para o setor, é fundamental para a manutenção destes resultados que sua força de trabalho possua uma qualificação que dê sustentabilidade às ações engendradas pelos gestores. Ressalta-se que a qualificação de seus trabalhadores não advém de uma política pública deliberada para tais questões (CRUZ et al. 2012), sendo que a maioria

REAd | Porto Alegre - Edição 82 - N 3 - setembro/dezembro 2015 - p. 622-647 
Wilson Aparecido Costa de Amorim, Marcus Vinicius Gonçalves da Cruz, Amyra Moyzes Sarsur \& André Luiz Fischer

das iniciativas se origina em uma bem articulada estrutura de educação corporativa (EBOLI et al., 2010) como política de gestão de pessoas.

O contexto geral é institucionalizado pela regulação da atividade bancária efetivada pelo Banco Central do Brasil (BACEN), cujas políticas caracterizam-se por serem implantadas majoritariamente por atores privados. Esta regulação em termos de certificação laboral tem por ponto de partida a Resolução 3.057 de 2002 do BACEN que estabeleceu condições específicas para a certificação de empregados das instituições financeiras que atuam no Brasil. De acordo com a resolução inicial, 25\% dos empregados que trabalhassem nas atividades de distribuição e mediação de títulos, valores mobiliários e derivativos, deveriam ser considerados aptos em exame de certificação até o final de 2006. Os exames e a consequente certificação ficariam a cargo de entidades de reconhecida capacidade técnica. Com o passar do tempo, outras certificações passaram a ser exigidas, o que possibilitou a consolidação das atividades de certificação em entidades como a Associação Brasileira das Entidades do Mercado Financeiro e Capitais (ANBIMA), a própria Federação Brasileira dos Bancos (FEBRABAN), a Associação Brasileira de Crédito Imobiliário e Poupança (ABECIP) e a Associação Brasileira de Bancos Comerciais (ABBC). Por sua vez, permitiu aos bancos a inserção, em suas práticas de gestão de pessoas, de processos de capacitação para certificação de seus trabalhadores em suas iniciativas de educação corporativa. Por seu turno, a representação sindical passa a inserir no contexto de negociação laboral as condições relacionadas aos processos de certificação, bem como discutir os impactos dessa dinâmica junto aos trabalhadores bancários.

O presente artigo analisa as políticas de gestão de pessoas e as iniciativas de educação corporativa junto ao movimento de certificação de trabalhadores bancários no Brasil, sob a égide destes distintos atores como o órgão regulador; os bancos e suas universidades corporativas; as certificadoras; os sindicatos e os bancários. Considera-se que o Estado brasileiro por meio Banco Central do Brasil modifica o contexto das competências no setor bancário induzindo à prática de certificação dos trabalhadores pelos bancos que atuam no Brasil. A pesquisa observa este quadro e aborda as relações existentes no interior dos bancos em termos de práticas de educação corporativa como política de gestão de pessoas realizadas para atender a essa função reguladora (em termos de normas setoriais e políticas de qualificação), bem como sua interação com entidades patronais (associações e federação) e dos trabalhadores (sindicatos).

REAd | Porto Alegre - Edição 82 - N 3 - setembro/dezembro 2015 - p. 622-647 
A análise segundo o ponto de vista desses distintos atores justifica-se uma vez que todos os agentes componentes da cadeia de valor do Sistema Financeiro Nacional vêm sendo afetados por estas dinâmicas (EBOLI, 2004). Além disso, o monitoramento da competitividade do setor bancário em termos de efetividade, confiabilidade e padrão de qualidade de operação são fatores de mensuração de atratividade de investimento e desenvolvimento dos países (LANVIN; EVANS, 2013). Assim, abarcam-se as políticas de qualificação por meio da educação corporativa no setor bancário considerando as condições ambientais externas e internas do setor, bem como as certificações profissionais (como são demandadas e obtidas), e identifica-se o papel dos principais atores envolvidos. Descreve-se também o processo de articulação das partes a partir do qual a certificação passa a ser exigida dos trabalhadores e iniciativas de educação corporativa das instituições financeiras estudadas.

\section{REFERENCIAL TEÓRICO}

\subsection{0 contexto da universidade corporativa}

Para Reis, Silva e Eboli (2010) a educação corporativa é, em uma definição, um conjunto de ações educacionais voltados para o desenvolvimento de competências individuais e organizacionais, que tem como missão favorecer o alcance dos objetivos organizacionais.

De modo geral, a questão da educação corporativa é um assunto vinculado à gestão de pessoas nas suas diversas instâncias, tanto organizacionais quanto individuais (EBOLI, 2008; BORGES-ANDRADE; ABBAD; MOURÃO; 2006). As referências conceituais oferecidas pela relação entre gestão por competências e educação corporativa, por exemplo, tornam-se relevantes uma vez que a dinâmica de sua implantação está articulada com a competitividade entre as organizações. Isto provoca a necessidade de estratégias voltadas para o alcance dos objetivos organizacionais, bem como o desenvolvimento da qualidade das pessoas na organização, sua valorização e retenção, além da sua capacidade de atrair novos indivíduos para os quadros organizacionais come práticas de gestão de pessoas (SARSUR, 2010; LANVIN; EVANS, 2013).

A contribuição da educação corporativa para o desenvolvimento do país torna-se inegável. Em um país como o Brasil, isto é ainda mais perceptível, pois a educação formal é deficiente, precária e desigual; e o acesso da população a ferramentas tecnológicas, por meio, por exemplo, dos programas de inclusão digital ainda é lento (CRUZ, 2010). A educação

REAd | Porto Alegre - Edição 82 - N 3 - setembro/dezembro 2015 - p. 622-647 
Wilson Aparecido Costa de Amorim, Marcus Vinicius Gonçalves da Cruz, Amyra Moyzes Sarsur \& André Luiz Fischer

corporativa possibilita ainda o incremento do conhecimento e acesso à informação para os próprios empregados, sejam eles fixos ou terceiros, na empresa ou em sua cadeia produtiva (EBOLI, 2004). Para Lanvin e Evans (2013) permite ainda o surgimento de oportunidades para os cidadãos e para a economia do país em geral, já que melhora e amplia os horizontes de conhecimento e acesso tecnológico, consequentemente, expandindo a capacidade competitiva das organizações e da nação, no cenário mundial.

Em termos organizacionais, as novas dinâmicas de gestão de pessoas impostas pela educação corporativa voltam-se para a superação dos antigos centros de treinamento aplicados a conteúdos específicos demandados por determinadas unidades organizacionais. Assim, chega-se então ao que se convencionou chamar de universidade corporativa, cuja articulação com a gestão de pessoas a insere em termos da estratégia organizacional em um patamar que permite uma orientação proativa e centralizadora a partir de um núcleo estratégico. A educação corporativa é sustentada por programas de educação permanente que, orientados com visão no futuro, antecipam e geram necessidades de melhoria, privilegiando os objetivos organizacionais, ainda que orientados para cada negócio dentro da empresa (BORGESANDRADE; ABBAD; MOURÃO; 2006; MEISTER, 1999; PEAK, 1997).

Eboli (2004) destaca que os vultosos investimentos para uma universidade corporativa são minimizados pela disseminação da cultura empresarial além de possibilitar parcerias externas que podem possibilitar uma nova fonte de renda. Como uma das ferramentas da estratégia organizacional, a educação corporativa relaciona-se também com dinâmicas de responsabilidade social corporativa, em um impulso utilitarista nos termos de Austin (2004), uma vez que ações de responsabilidade social são meios de motivar e reter empregados, de conquistar apoio de consumidores e investidores, gerando claras vantagens competitivas.

Na perspectiva de Eboli, Fischer, Moraes e Amorim (2010) os fundamentos da educação corporativa vão ganhando importância, evoluindo em termos de difusão e novos projetos, ressaltando a noção de vantagem competitiva como um benefício resultante da valorização da educação. Isto reforça a conexão com um dos sete princípios e práticas de sucesso de um sistema de educação corporativa, propostos por Eboli (2004, p.59) envolvendo (i) competitividade; (ii) perpetuidade; (iii) conectividade; (iv) disponibilidade; (v) cidadania; (vi) parceria; e (vii) sustentabilidade. Além do princípio da competitividade, voltado para a transformação do indivíduo em fator de diferenciação da organização,; destacam-se aqui os princípios de perpetuidade em que o processo de aprendizagem é transmitido de modo a

REAd | Porto Alegre - Edição 82 - N 3 - setembro/dezembro 2015 - p. 622-647 


\section{BANCÁRIA: DISTINTOS ATORES E PERSPECTIVAS}

consolidar a perenidade da organização ao longo do tempo; a conectividade, que fortalece a rede em termos de qualidade e quantidade de relacionamentos com o público interno e externo; a disponibilidade de atividades e recursos educacionais ao usuário a tempo e a hora; a cidadania individual e corporativa em termos de comportamento ético e socialmente responsável; da parceria, fortalecendo as conexões voltadas para as competências internas e externas; além dos resultados organizacionais em termos de sustentabilidade. Diante da velocidade das mudanças, Eboli (2004, p.128) enfatiza a necessidade de "criar um ambiente e um processo de trabalho que estimulem a geração de novos conhecimentos e novas conexões e aplicações de conhecimentos já existentes”. Esses princípios fundamentam a utilização da prática reflexiva como um mecanismo de aprendizado que possibilita ao indivíduo fazer conexões entre a teoria e a prática organizacional durante a própria realização do trabalho, de forma acessível, flexível, dinâmica e eficaz, numa constante (re)aplicação de conhecimentos.

Hourneaux Júnior, Eboli, e Martins (2008, p.115) descrevem em pesquisa as características das ações de educação corporativa em distintas firmas no Brasil. Os autores revelaram a importância desses princípios em um movimento de adaptação e crescimento com base em estruturas flexíveis e eficazes voltadas para o "desenvolvimento de competências dos indivíduos necessárias para a manutenção da competitividade dos negócios”, bem como de estruturas de ensino à distância por meio do e-learning.

Eboli (2004) mostra ainda a educação corporativa como ferramenta estratégica das instituições financeiras. A autora aponta que os bancos são importantes pela sua abrangência nacional, estruturação de sólidas parcerias para implantação e operacionalização de seus projetos de educação corporativa, juntamente àqueles de responsabilidade social nos termos de Austin (2004). Os bancos têm ainda seus projetos sustentados pela profícua criação de institutos e fundações para darem suporte a suas universidades corporativas e ações sociais. Também são de destaque sua articulação em rede e disseminação do conhecimento em plataformas internas e externas favorecendo o intercâmbio e fortalecimento da sua imagem e reputação a partir da obtenção e devida divulgação de prêmios e homenagens, possibilitando às instituições financeiras a ampliação de sua interação com a sociedade e fidelização de clientes cada vez mais atentos a este foco.

\subsection{O sistema bancário no Brasil}

REAd | Porto Alegre - Edição 82 - N 3 - setembro/dezembro 2015 - p. 622-647 
Wilson Aparecido Costa de Amorim, Marcus Vinicius Gonçalves da Cruz, Amyra Moyzes Sarsur \& André Luiz Fischer

Uma das funções da autoridade monetária de um país é a supervisão bancária, voltada para monitorar e avaliar diuturnamente o seu sistema financeiro e suas instituições, de modo a manter seu pleno funcionamento e credibilidade. As preocupações relacionadas à solvência das instituições financeiras, à dinâmica dos mercados de crédito e de capitais, à evolução dos preços dos principais ativos da economia e aos luxos de capitais são fundamentais para o equilíbrio do sistema financeiro. Os reflexos de uma crise global como a de 2008 - que ainda estão presentes - mais do que justificam estas preocupações.

O cenário estrutural vigente no sistema financeiro nacional do Brasil resulta do ordenamento do setor bancário que se desenvolveu desde meados dos anos 1990. Notadamente após o Plano Real, o BACEN passou a ocupar uma posição central na condução da política econômica, dado seu papel na determinação das taxas de juros e câmbio e - já nos anos 2000 - na condução da política de metas de inflação (PRATES, 2010). No que se refere à estrutura do setor, a partir de diretrizes do governo central, nos anos 1990, houve redução na quantidade de bancos estaduais e bancos privados nacionais, e a rápida evolução na participação de mercado das instituições financeiras estrangeiras (GALVÃO, 2010). Em função dessas mudanças, as organizações bancárias atuantes no mercado brasileiro passaram por um processo de reestruturação cuja base era o aumento da eficiência para melhorar sua competitividade, o aprimoramento de seus produtos e serviços e a diminuição dos custos para os clientes com o objetivo de fidelizá-los, concomitantemente à introdução de novas tecnologias de gestão que levaram à expressiva diminuição de postos de trabalho bancário naquela década (CERQUEIRA; AMORIM, 1997; GÓES; SOUZA, 2008).

Com as turbulências enfrentadas desde 2008 pelo setor financeiro global, houve um desenrolar de ações distintas das instituições financeiras. Tais ações, por vezes contraditórias, envolveram compras, vendas, fusões, desmembramentos, incorporações, privatizações, estatizações, segmentação e até o encerramento de operações. No caso brasileiro, o impacto dessa situação foi minimizado por medidas de acompanhamento da autoridade monetária e medidas de expansão das operações de crédito. Desde então, essa reconfiguração do sistema financeiro brasileiro vai se consolidando, embora seja possível visualizar algumas particularidades. Em primeiro lugar, o que permanece é a tendência à concentração do setor. Segundo dados do BACEN (2013), em 2004 os 5 maiores bancos detinham 50\% dos ativos totais do segmento bancário enquanto em 2012 esses mesmos bancos possuíam aproximadamente $67 \%$ dos ativos totais, o que demonstra que não houve uma inversão do 


\section{BANCÁRIA: DISTINTOS ATORES E PERSPECTIVAS}

processo de concentração do setor durante os governos recentes. Por sua vez, a retomada do crescimento econômico nos anos 2000 possibilitou lento crescimento do emprego bancário, que chegou a cerca de 490 mil trabalhadores em dezembro de 2010 (DIEESE, 2012).

A trajetória das organizações do ramo financeiro brasileiro nos últimos dez anos se pautou por uma estratégia de fortalecimento e crescimento. As contas no setor bancário cresceram de 55,7 milhões para 91.9 milhões entre 2002 e 2011; o sistema lida com cerca de o 174.8 milhões de correntistas, 21.278 agências e 175 mil terminais de autoatendimento, com a totalidade dos municípios brasileiros dispondo de serviços bancários (BACEN, 2013). Outra dimensão importante do setor bancário é valor total de ativos do sistema financeiro brasileiro, com taxa média de crescimento anual de 20\%, montando cerca de R\$ 5 trilhões em fins de 2012. Os resultados das análises mensais para riscos de crédito e de mercado, e diárias para risco de liquidez realizadas pelo BACEN junto aos bancos do país, indicam que, mesmo em situações de fortes impactos econômicos e financeiros, o Sistema Financeiro Nacional (SFN) manteve níveis adequados de capitalização, liquidez e baixa dependência de recursos externos (BACEN, 2013).

Outros pontos de destaque na configuração do sistema bancário nacional apontam para um processo crescente de "bancarização", o aumento da oferta de crédito e o fortalecimento dos bancos públicos. A bancarização é um processo que pode ser entendido como a busca por ampliação da capilaridade das operações bancárias. Segundo a FEBRABAN (2011), esta não se confunde com a posse de conta corrente, pois pode-se constatar a bancarização com base no nível de acesso a serviços financeiros e o grau de uso dos serviços financeiros. Seu grau pode ser medido por indicadores como o uso do autoatendimento, internet banking, débito automático, depósito, correspondentes bancários, entre outros. A Tabela 1 fornece a evolução desses indicadores:

Tabela 1 - Transações bancárias (em milhões) - 2006 - 2010

\begin{tabular}{lrcc}
\hline & $\mathbf{2 0 0 6}$ & $\mathbf{2 0 1 0}$ & Variação \\
\hline Automáticas & 9.709 & 11.761 & $21,14 \%$ \\
Autoatendimento & 13.735 & 17.790 & $29,52 \%$ \\
Internet Banking & 6.937 & 12.812 & $84,69 \%$ \\
Pontos de Vendas no Comércio & 1.700 & 2.320 & $36,47 \%$ \\
Caixas de Agências e PABs & 4,281 & 5.213 & $21,77 \%$ \\
Call Center & 1,319 & 1.606 & $21,76 \%$ \\
Correspondentes Bancários & 1.845 & 3.097 & $67,86 \%$
\end{tabular}

REAd | Porto Alegre - Edição 82 - N 3 - setembro/dezembro 2015 - p. 622-647 
Wilson Aparecido Costa de Amorim, Marcus Vinicius Gonçalves da Cruz, Amyra Moyzes Sarsur \& André Luiz Fischer

\begin{tabular}{lrrr} 
Cheques Compensados & 1.533 & 1.120 & $-26,94 \%$ \\
\hline TOTAL & $\mathbf{4 1 . 0 5 9}$ & $\mathbf{5 5 . 7 1 9}$ & $\mathbf{3 5 , 7 0 \%}$ \\
\hline \multicolumn{4}{c}{ Fonte: FEBRABAN $(2011)}$.
\end{tabular}

O crescimento expressivo das transações realizadas via internet banking e também dos correspondentes bancários não só demonstram o aumento do grau de bancarização, como também são expressão de uma outra estratégia que vem sendo implantada pelos bancos, qual seja a externalização das atividades bancárias a fim de que as agências se transformem em lócus de venda de produtos e serviços aos clientes.

A evolução da bancarização também é um processo atrelado ao aumento da oferta de crédito pelo setor bancário durante os anos 2000. A melhora progressiva dos fundamentos macroeconômicos e as políticas de estímulo à ampliação do crédito e de acesso aos serviços financeiros criaram um ambiente em que os bancos aumentaram a oferta de crédito ao setor privado da economia e, dentro desse, às famílias, nas modalidades de crédito pessoal, aquisição de veículos e cartão de crédito (PRATES, 2010). As expectativas otimistas acerca da recuperação do emprego e da renda sob o governo Luís Inácio Lula da Silva colocaram os bancos privados, nacionais e estrangeiros, à frente desse processo. Além disso, há uma estratégia dos bancos de ampliar o número de clientes para segmentos até então não incluídos no sistema, pois uma de suas principais fontes de receita passou a ser a cobrança dos serviços.

O Banco Central do Brasil (BACEN, 2013) sinaliza que a regulação no Brasil, hoje em dia, adota como política a exigência aos bancos de melhores práticas no gerenciamento de riscos e controles internos e na área de governança corporativa. Em consequência, as práticas de inspeção - antes orientadas basicamente para a análise de demonstrativos contábeis centrada individualmente em instituições - passaram a se preocupar com a saúde e a solvência do sistema como um todo, em um contexto cada vez maior de interconexão entre as instituições globais e os mercados. O cenário da atividade bancária nacional demonstra a importância das representações institucionais das organizações do setor bem como dos trabalhadores, que também devem ser considerados atores relevantes no processo.

\section{PROCEDIMENTOS METODOLÓGICOS}

Os procedimentos metodológicos privilegiaram a abordagem de natureza qualitativa (FLICK, 2004), dado que o foco foi delineado pela análise da relação entre os processos de REAd | Porto Alegre - Edição 82 - N 3 - setembro/dezembro 2015 - p. 622-647 


\section{BANCÁRIA: DISTINTOS ATORES E PERSPECTIVAS}

educação corporativa e os mecanismos de certificação nas instituições financeiras. Quanto à sua finalidade, a pesquisa realizada foi analítico-descritiva, tendo como objetivo delinear as características de determinada população ou fenômeno (CRESWELL, 2010).

Os principais atores selecionados para a pesquisa foram o Banco Central do Brasil (BACEN), representando a visão do Estado por meio do órgão regulador, uma entidade certificadora do setor bancário, e três instituições financeiras denominados "Banco A", “Banco B” e "Banco C” (dentre os 10 maiores do país, todos de capital nacional, todos com universidade corporativa como política de gestão de pessoas). Como síntese da perspectiva das organizações, a Confederação dos Trabalhadores do Ramo Financeiro (CONTRAF) como indicadora do ponto de vista da representação coletiva dos trabalhadores e a Federação Brasileira dos Bancos (FEBRABAN) como síntese da perspectiva patronal.

Os instrumentos de coletas de dados foram a análise documental, entrevistas e grupo de foco. Os documentos analisados mostraram quais foram as políticas, diretrizes, e procedimentos utilizados pelos principais atores estudados - a entidade reguladora e legislação pertinente, as universidades corporativas dos bancos, as representações de trabalhadores e dos patrões (e respectivas perspectivas de reivindicações); e as instituições certificadoras. A análise destes documentos permitiu uma complementação dos dados obtidos nas onze entrevistas e um grupo focal realizado com vinte participantes, conforme o Quadro 1.

O grupo de foco foi utilizados para coligir dados relativos a impressões e opiniões de um grupo maior de pessoas envolvido em uma situação comum (COLLIS, HUSSEY, 2005).

Nas entrevistas semiestruturadas houve a interação necessária entre pesquisador e pesquisado para detectar a dinâmica do processo de certificação segundo a percepção do entrevistado (CRESWELL, 2010). Todos os onze entrevistados solicitaram o resguardo das fontes, sendo mantido o ético sigilo para obtenção das opiniões.

Quadro 1 - Entidades/organização, entrevistas e grupo de foco

\begin{tabular}{|l|l|l|}
\hline Entidade/Organização & Entrevistas/grupo focal & Características dos gestores \\
\hline BACEN & $\begin{array}{l}\text { Entrevistados } 1 \text { e } 2 \\
\text { Entrevistados 3 e 4 }\end{array}$ & $\begin{array}{l}\text { - nível estratégico } \\
\text { - staff }\end{array}$ \\
\hline Banco A & Entrevistados 5, 6 e 7 & $\begin{array}{l}- \text { nível estratégico (gestão de pessoas, } \\
\text { competências, avaliação e certificação) }\end{array}$ \\
\hline Banco B & $\begin{array}{l}\text { - nível estratégico (gestão de pessoas, } \\
\text { competências, avaliação e certificação) }\end{array}$ \\
\hline Banco C & $\begin{array}{l}\text { - nível estratégico (gestão de pessoas, } \\
\text { competências, avaliação e certificação) }\end{array}$ \\
\hline Certificadora & Entrevistado 10 & -gestor educação corporativa \\
\hline
\end{tabular}

REAd | Porto Alegre - Edição 82 - N 3 - setembro/dezembro 2015 - p. 622-647 
Wilson Aparecido Costa de Amorim, Marcus Vinicius Gonçalves da Cruz, Amyra Moyzes Sarsur \& André Luiz Fischer

\begin{tabular}{|l|l|l|}
\hline Sindicato Patronal & Entrevistado 11 & - gestor educação corporativa \\
\hline Sindicato Laboral & Grupo de Foco & -20 sindicalistas de todo o país \\
\hline
\end{tabular}
Fonte: Dados da Pesquisa.

Os pesquisadores também recorreram à observação participante (LAVILLE, 1999), comparecendo a dois fóruns de discussão entre FEBRABAN e sindicalistas com profissionais e acadêmicos sobre a gestão bancária e participação do empregado no desenvolvimento das relações de trabalho, além de treze visitas às sete instituições selecionadas.

\section{APRESENTAÇÃO E ANÁLISE DE RESULTADOS}

A partir da pesquisa realizada junto aos principais atores da área bancária nacional, as ações de educação corporativa nas instituições financeiras e entre elas aquelas voltadas para a certificação profissional chamam a atenção. Cabe ressaltar que os bancos são organizações críticas para uma economia, pois proporcionam financiamento para empreendimentos comerciais, serviços financeiros básicos para a população e acesso aos sistemas de pagamento. Em todo mundo, a indústria bancária é alvo de regulação pelo Estado e, por isto, sólidos instrumentos de governança corporativa são indispensáveis (BACEN, 2013).

A importância das representações institucionais das organizações do setor, bem como dos trabalhadores, destaca-se no cenário de expansão da atividade bancária. Do lado patronal, a FEBRABAN - fundada na segunda metade dos anos 1960 - é a principal entidade representativa do setor bancário brasileiro. Seu compromisso é o fortalecimento do sistema financeiro e de suas relações com a sociedade, além da contribuição para o desenvolvimento econômico, social e sustentável do país. Seu quadro associativo da entidade tinha 125 dos 178 bancos registrados no BACEN em fevereiro de 2013. Sua representação ocorre em todas as esferas - Poderes Executivo, Legislativo e Judiciário e entidades representativas da sociedade -, acompanhando o aperfeiçoamento do sistema normativo, e visando a melhoria da produção e a redução dos níveis de risco. Com sua característica discrição, o setor sempre foi influente política e economicamente nos diferentes governos (MINELLA, 2007).

A FEBRABAN esforça-se para modificar de uma imagem de instituição que protege os bancos para uma entidade que dialoga com a sociedade. Sua estratégia é incentivar a melhoria na prestação de serviços por seus associados. Além disso, intenciona promover junto aos trabalhadores do setor o resgate do "orgulho de ser bancário, valorizando suas competências”, de modo que a sociedade possa reconhecer os atributos daquele tipo de REAd | Porto Alegre - Edição 82 - N 3 - setembro/dezembro 2015 - p. 622-647 


\section{BANCÁRIA: DISTINTOS ATORES E PERSPECTIVAS}

organização (Entrevistado 11). Os seus principais projetos envolvem: a promoção da cidadania e da educação financeira; diálogo com a sociedade; compromissos com o desenvolvimento socioeconômico sustentável; e o aperfeiçoamento do sistema financeiro nacional em benefício da sociedade. A FEBRABAN também visa o crescente acesso da população em relação a produtos e serviços financeiros, “inclusive com iniciativas de programas de educação financeira para sua clientela e população em geral” (Entrevistado 11).

Entre os trabalhadores, a instituição de maior representatividade no país é a Confederação Nacional dos Trabalhadores do Ramo Financeiro, associada à Central Única dos Trabalhadores (CONTRAF-CUT) criada em 2006 (a partir da Confederação Nacional dos Bancários - CNB CUT de 1992). Dentre seus principais objetivos está o atendimento das demandas das categorias de trabalhadores envolvidas em atividades do sistema financeiro. Há trabalhadores que, embora realizem serviços contratados por empresas que fazem parte das holdings controladas por bancos, não são bancários e assim permanecem à margem da Convenção Coletiva Nacional dos Bancários. Segundo a CONTRAF-CUT, tais categorias promotores de vendas, securitários, especialistas em tecnologia da informação, funcionários de bolsas de valores, entre outros - somadas aos bancários ultrapassavam um milhão de empregados em 2013. Um dos objetivos da criação da entidade foi incluir no debate e nas negociações sindicais todos os trabalhadores que fazem parte do processo de intermediação financeira. O intuito é equiparar seus direitos e ampliar suas conquistas. Para a CONTRAFCUT a organização sindical por categoria profissional no caso bancário tornou-se obsoleta uma vez que há vários tipos trabalhadores envolvidos no mesmo ramo de atividade.

No entanto, é importante salientar que há aspectos da contratação do trabalho bancário que também são influenciados pela de ação de outros atores institucionais. Um exemplo claro são as pressões externas advindas do posicionamento institucional do BACEN, que passou a regular alguma das circunstâncias relacionadas com a busca de competências dos operadores do sistema financeiro nacional, como a certificação profissional.

Na área bancária, a disseminação da certificação segue pouco estudada, mas institucionalmente, sua articulação se mostra, porém, robusta quanto aos parceiros e números envolvidos. No meio bancário, o processo de certificação envolve o trabalhador bancário e mais quatro atores: as associações patronais certificadoras - ANBIMA, FEBRABAN, ABECIP e ABBC; o órgão regulador - BACEN; os bancos empregadores; e os sindicatos.

REAd | Porto Alegre - Edição 82 - N 3 - setembro/dezembro 2015 - p. 622-647 
Wilson Aparecido Costa de Amorim, Marcus Vinicius Gonçalves da Cruz, Amyra Moyzes Sarsur \& André Luiz Fischer

A pesquisa identificou o Banco Central como um dos pilares no processo de certificação, uma vez que é atividade finalística da instituição a regulação e supervisão do sistema financeiro nacional. Nas entrevistas e documentos, verificou-se que a certificação do trabalho bancário veio no bojo da inclusão bancária, "uma vez que esta desenvolve a cidadania... e o cidadão passa a participar do processo econômico, a certificação fortalece a política de fiscalização e regulação" (Entrevistado 1). A introdução da figura do "correspondente bancário" (Resoluções BACEN nº 3.954 e 3.959 de fevereiro e março de 2011), como possibilidade de pulverizar o a acesso a serviços financeiros em localidades que não tenham agência bancária, utilizando-se de supermercados, correios, padarias, casas lotéricas etc, também está imbricada à intenção da inclusão bancária.

Os contornos deste contexto são constatados tanto pela saúde financeira das instituições bancárias no Brasil equanto pela ampliação da inclusão bancária no país nos anos 2000. Na visão do BACEN, para a expansão do crédito é necessário garantir a sua qualidade, uma vez que é a instituição financeira que responde junto ao Banco Central quando há algum tipo de problema, e não o empregado. O propósito de segurança para o sistema bancário no país a partir da dinâmica de inclusão bancária e expansão do crédito influenciou o contexto da certificação. Na esteira do incremento da venda de produtos e serviços bancários surgiram muitas reclamações dos clientes, e "daí a necessidade de pressionar as instituições componentes do sistema financeiro a falar a linguagem adequada ao cidadão” (Entrevistado 1). A educação financeira, tanto da instituição quanto da pessoa que compra o produto ou serviço financeiro, torna-se importante, porque "muitas das vezes o vendedor não sabe do ponto de vista técnico nem ético o que significa o que ele vende, é uma questão que a instituição atrás do balcão deve refletir” (Entrevistado 2).

No início dos anos 2000, o Banco Central delineou uma consulta a instituições como ANBID, ANDIMA e Banco do Brasil para verificar a dinâmica das reclamações dos clientes que chegaram ao PROCON ou Ministério Público antes de chegar ao BACEN. Para o Entrevistado 3 "havia necessidade de uma rede de regulação para melhoria da relação com o cliente”, “...é o cliente quem estipula em ultima instância a necessidade". Além disso, por diversas vezes foi ressaltado pelos entrevistados que "a imagem ruim de banco ruim é também ruim para o Sistema Financeiro Nacional” (Entrevistado 4).

A Resolução 3.057, de 2002 do BACEN estabeleceu condições específicas para a certificação de empregados das instituições financeiras e demais instituições autorizadas. A 


\section{BANCÁRIA: DISTINTOS ATORES E PERSPECTIVAS}

resolução previa que 25\% dos empregados que exercessem as atividades de distribuição e mediação de títulos, valores mobiliários e derivativos, deveriam ser considerados aptos em exame de certificação organizado por entidade de reconhecida capacidade técnica até o final de 2006. O Conselho Monetário Nacional (CMN) também estendeu a certificação aos empregados das cooperativas de crédito e sobre a atuação dessas instituições na distribuição de cotas de fundos de investimento em agosto de 2005 (Resolução 3.309 do BACEN).

As associações de classe representativas de instituições do mercado financeiro reclamaram que tal cronograma para certificação dificilmente conseguiria ser atendido pelo elevado número de empregados a serem treinados. Porém, de acordo com um dos entrevistados "o mercado se organizou bem para a certificação via ANBID. A ANBID veio ao BACEN e mostrou o que fazia - as provas, conteúdos, processos de certificação etc” (Entrevistado 2). A edição da resolução movimentara então instituições e empregados: os bancos, pela possível sanção da entidade reguladora e os empregados, individualmente, por melhores condições de carreira e emprego. O BACEN destaca os efeitos daquela decisão:

“...a eventual flexibilização do programa de certificação inicialmente levado a efeito não comprometeria os resultados futuros quanto à qualificação dos empregados do setor financeiro, nem mesmo diminuiria a demanda por treinamento desses profissionais, ...já existe uma cultura entre as instituições de que a qualificação de seus empregados em um ambiente competitivo é fundamental para a preservação da respectiva clientela.” (BACEN, 2003)

Para melhorar a qualificação dos empregados das instituições que trabalham com produtos financeiros, o CMN modificou o cronograma inicialmente definido, de modo que o programa de certificação fosse cumprido (percentuais mínimos de pessoal certificado: 25\% no ano de 2004; 50\% no ano de 2005; 75\% no ano de 2006 e 100\% no ano de 2007), bem como que, a partir de $1^{\circ}$ de janeiro de 2008, os serviços fossem realizados sempre por pessoas devidamente certificadas. Porém, para os empregados contratados para o exercício das atividades de distribuição e mediação de títulos, valores mobiliários e derivativos, a partir da data da resolução, os mesmos deveriam ser certificados no prazo de um ano (a partir da data da respectiva contratação, não podendo esse prazo exceder o final do ano de 2007). Ao final, a resolução apontava para o contexto que se perpetuaria em termos do mercado e dos trabalhadores quanto ao processo de certificação:

“...considerando que a cultura da necessidade de aprimoramento da qualificação técnica das pessoas que negociam com ativos e modalidades financeiras vêm

REAd | Porto Alegre - Edição 82 - N 3 - setembro/dezembro 2015 - p. 622-647 
Wilson Aparecido Costa de Amorim, Marcus Vinicius Gonçalves da Cruz, Amyra Moyzes Sarsur \& André Luiz Fischer

experimentando nível de crescimento bastante significativo, e (...) muitas instituições mantêm centros de treinamento ou vêm celebrando convênios com entidades especializadas em treinamentos voltados para os mercados financeiros e de capitais, o CMN resolveu deixar a cargo das próprias instituições a tarefa de providenciar a renovação da certificação de seus empregados, que poderá ser feita de forma continuada ou de acordo com as peculiaridades dos mercados em que atuam, sem que haja necessidade de especificar-se prazo ou data para que os empregados sejam submetidos a novos exames.” (BACEN, 2003)

A ANBIMA é principal certificadora de profissionais do mercado financeiro brasileiro, com mais de 600 mil certificações emitidas (Tabela 2). A Associação Brasileira das Entidades dos Mercados Financeiro e de Capitais (ANBIMA) é uma entidade representativa de 340 associados (dos bancos de investimentos, bancos múltiplos gestores e administradores de fundos, corretoras e distribuidoras de valores mobiliários e gestores de patrimônio com carteira de investimento - que operam no mercado de capitais). Ela resultou da fusão entre a Associação Nacional dos Bancos de Investimento (ANBID) e a Associação Nacional das Instituições do Mercado Financeiro (ANDIMA) em outubro de 2009. Entre outros objetivos, a ANBIMA pretende autorregular as atividades dos associados (por meio de adesão voluntária a códigos e melhores práticas de negócios); e contribuir para a qualificação de profissionais e investidores brasileiros. Para o Entrevistado 8, a experiência na formação de operadores das Bolsas de Valores facilitou a inserção da ANBIMA como certificadora. O significativo número de certificados (Tabela 2) dá uma dimensão de trabalhadores mobilizados, quase 1\% daqueles com carteira assinada no país em 2013.

Tabela 2 - Dados consolidados dos Exames de Certificação (dados até 31/12/2013)

\begin{tabular}{|c|c|c|c|c|c|c|c|c|c|}
\hline Situação & \multicolumn{2}{|c|}{$\begin{array}{c}\text { CPA-10 } \\
\text { (início em 2003) }\end{array}$} & \multicolumn{2}{|c|}{$\begin{array}{c}\text { CPA-20 } \\
\text { (início em 2002) }\end{array}$} & \multicolumn{2}{|c|}{$\begin{array}{c}\text { CGA } \\
\text { (início em 2009) }\end{array}$} & \multicolumn{2}{|c|}{$\begin{array}{c}\text { CEA } \\
\text { (início em 2009) }\end{array}$} & Total \\
\hline Inscrições & \multicolumn{2}{|c|}{505.003} & \multicolumn{2}{|c|}{112.923} & \multicolumn{2}{|c|}{900} & \multicolumn{2}{|c|}{1.829} & 620.655 \\
\hline $\begin{array}{l}\text { Exames } \\
\text { realizados }\end{array}$ & 481.179 & $95 \%$ & 106.438 & $94 \%$ & 841 & $93 \%$ & 1.781 & $97 \%$ & 590.239 \\
\hline Aprovações & 278.423 & $58 \%$ & 59.555 & $56 \%$ & 256 & $30 \%$ & 749 & $42 \%$ & 338.983 \\
\hline Ausências & 23.824 & $5 \%$ & 6.485 & $6 \%$ & 59 & $7 \%$ & 48 & $3 \%$ & 30416 \\
\hline
\end{tabular}

Fonte: ANBIMA, 2014.

A Certificação Profissional ANBIMA 10 (CPA-10), e Certificação Profissional ANBIMA 20 (CPA-20) certificam profissionais que respectivamente: a) comercializam e distribuem de produtos de investimento diretamente ao público investidor em agências bancárias e de cooperativas de crédito; b) que comercializam e distribuem de produtos de investimento diretamente aos investidores qualificados, de segmentos private, corporate, investidores institucionais (inclusive de centrais de atendimento e gerentes de agência). 


\section{BANCÁRIA: DISTINTOS ATORES E PERSPECTIVAS}

A Certificação de Gestores ANBIMA (CGA) e Certificação Especialista de Investimento ANBIMA (CEA) destinam-se aos profissionais que tratam da gestão remunerada de recursos de terceiros, possuindo poderes para tomar decisões de investimento; que assessoram decisões de investimento em agências bancárias ou plataformas de atendimento a clientes, potenciais investidores e gerentes. A certificação está relacionada às atividades desenvolvidas (comercialização ou influências no processo de tomada de decisão do investidor) e não aos cargos, ressaltam os descritores dos diversos cursos.

Os mecanismos institucionais para além da certificação também foram aprimorados. O BACEN elaborou métricas para os bancos (como o número de reclamações dos clientes) e exigiu a criação de uma ouvidoria nas instituições financeiras, elaborando uma normatização do Serviço de Atendimento ao Cliente dos bancos. A chamada “Ouvidoria” é a última instância de reclamação do cliente antes do BACEN. “A ouvidoria é desaguadouro de várias iniciativas e processos de fiscalização, acompanhamento das reclamações; todos os funcionários da ouvidoria devem ser certificados; há um ouvidor e um diretor responsável pela ouvidoria que é a última instância no banco” (Entrevistado 4).

A FEBRABAN também se tornou certificadora por meio da "Certificação Profissional FEBRABAN Correspondente” para atender a Resolução nº 3.954 do CMN (capacitação e certificação dos agentes envolvidos no atendimento aos clientes do correspondente bancário). Os diversos segmentos de mercado afetados pela nova regulamentação de Correspondentes têm especificidades e por isto há quatro programas: um que certifica o candidato a atuar em qualquer modalidade (completo); e outros três que visam à certificação dos profissionais que pretendam atuar ou já atuam em apenas algum destes segmentos do mercado consignado, crédito direto ao consumidor e veículos. Esse desmembramento permite que de cada candidato seja exigido conhecimento mais específico para o segmento de atuação a que se dedique em sua atividade profissional (Entrevistado 11). Novamente verifica-se a mobilização das entidades do mercado voltando-se para atender a demandas da entidade reguladora e, neste caso, não por acaso para profissionais não bancários. Assim, a entidade criou uma unidade de educação corporativa em 2013, o Instituto FEBRABAN de Educação (INFI), visitado durante a pesquisa, voltado para a educação financeira, inclusive para a sociedade, visando inclusão financeira, além de educação profissional por meio de curso de especialização. A ideia segundo o Entrevistado 11 é "formar mão de obra para evitar um apagão” nos próximos anos, além de “aproximar o setor bancário de stakeholders como a

REAd | Porto Alegre - Edição 82 - N 3 - setembro/dezembro 2015 - p. 622-647 
Wilson Aparecido Costa de Amorim, Marcus Vinicius Gonçalves da Cruz, Amyra Moyzes Sarsur \& André Luiz Fischer

própria sociedade, bancários, bancos de pequeno porte e bancos de grande porte”. Isto aponta para um movimento da entidade patronal em mobilizar iniciativas de educação corporativa voltadas para ampliar as competências organizacionais de seus afiliados via capacitação dos trabalhadores.

Para os bancos, o contexto gerado pela possibilidade de utilização do correspondente bancário é vantajoso pela redução de custos na oferta de serviços já que a contratação do trabalhador no correspondente bancário é menor que a dos bancários. Os entrevistados do BACEN reconheceram que os bancos chegaram a alocar correspondentes bancários dentro das agências, o que levou o órgão regulador a lançar uma normativa proibindo esta situação para combater um "desvirtuamento do modelo proposto" (Entrevistado 1). Porém, de acordo com o Entrevistado 3, “é preciso ter cuidado com o que vai ser normatizado via certificação porque isto implica em custos para as empresas; há um cuidado para não se impor custos desnecessários para o sistema, verifica-se sempre a potencial fonte de riscos para a adoção das medidas”. Assim, antes da aprovação de novas normativas as questões de regulamentação são sempre discutidas com os principais agentes do mercado. Para o Entrevistado 4 “...os bancos inicialmente viram a certificação como 'custo', mas ao longo do tempo essa percepção foi mudada para investimento”, mobilizando as áreas de gestão de pessoas naquelas firmas.

O Banco A tem sido parte integrante das consultas do Banco Central quando da normatização do mercado financeiro, dada sua estrutura e tamanho e por isto foi tomado como referência da visão patronal. Este banco, bem como outros, participa da discussão das normas de certificação diretamente ou via suas entidades de representação. Quando a norma é aprovada pelo BACEN, eles a acatam e então induzem seus empregados a obtê-la. Possui iniciativas de educação corporativa desde os anos 1960, que se "alinham-se com o direcionamento estratégico do Banco A” (Entrevistada 7) e contribuem para a realização da missão do banco, a concretização de sua visão de futuro e o desenvolvimento de suas crenças e valores, consolidando o compromisso da organização com os acionistas, os clientes, a sociedade e os funcionários.

As entrevistas no Banco A revelaram que a partir da definição da estratégia corporativa, a instituição sistematiza suas competências organizacionais bem como as competências individuais que as suportam. Segundo o Entrevistado 5, “...há um mapeamento por competências e relaciona-se o tipo de competência com os conhecimentos necessários, tanto os que o indivíduo traz quanto os que ele precisa, ... o sistema está no Banco A como 


\section{BANCÁRIA: DISTINTOS ATORES E PERSPECTIVAS}

um todo”. Toda a gestão de pessoas é norteada por este processo, uma vez que foram mapeadas em torno de 2.000 competências mapeadas, de acordo com a especificidade do cargo, aí inclusa as vinculadas às certificações. A partir desse mapeamento também "são elencadas as necessidades a serem trabalhadas na universidade corporativa” (Entrevistada 5).

A Diretoria de Recursos Humanos (DRH) é responsável pelo processo de mapeamento das competências com segmentação por cargos. Após o processo seletivo para entrada no banco, os empregados entram nos segmentos de cargos. Os bancários são agrupados como público alvo de acesso às carreiras e isto pode envolver as certificações (as certificações legais são obrigatórias), estando disponíveis na universidade corporativa os cursos para obtenção do conhecimento necessário para submissão aos testes da ANBIMA. Uma vez que para chegar ao cargo de gerente, o funcionário precisa das CPA 10 e 20, há um programa interno que permite sua capacitação, bem como o custeio da certificação. Além disso, sistemas corporativos alertam ao empregado da necessidade de renovação e atualização.

Um achado importante da pesquisa é que a instituição A, por meio de sua base de dados de empregados, mantém um cadastro de indivíduos na casa de dezenas de milhares de funcionários, tanto para incentivar o aprimoramento de suas competências por meio dos cursos da universidade corporativa, tanto para incentivar a certificação. Como estratégia de gestão de pessoas, mantém uma proporção de 3,3 funcionários certificados para cada cargo que exige certificação. Assim, focam como público alvo os ocupantes das posições iniciais da carreira, principalmente o cargo de escriturário/caixa, assistente de negócio e gerente. Segundo o Entrevistado 6 “...os assistentes de negócio já devem ter a certificação, têm que estar preparados para assumir a gerência”. Isso movimenta os processos de educação corporativa, “articulados constantemente com as necessidades internas do Banco A”.

O Banco A reforça a dinâmica da certificação legal (como as CPA-10 e CPA-20) e também a Certificação Interna, e entende que ela gera benefícios dentro da organização, principalmente no processo de carreira. Para o Entrevistado 7, “...a criação das certificações tem mão dupla: bancos sugerem, BACEN cria norma. BACEN cria norma e bancos aceitam”. Daí os bancos alimentam os processos de capacitação profissional via educação corporativa e o ciclo se mantém. A princípio, os gestores do Banco A não tem como auferir os resultados diante da gama de pessoas certificadas, mas os entrevistados intuem que seja positiva e que por isto, outros tipos potenciais de certificação são avaliados pelo banco, em conjunto com a

REAd | Porto Alegre - Edição 82 - N 3 - setembro/dezembro 2015 - p. 622-647 
Wilson Aparecido Costa de Amorim, Marcus Vinicius Gonçalves da Cruz, Amyra Moyzes Sarsur \& André Luiz Fischer

universidade corporativa. No entanto, o Entrevistado 6 alerta que a “...certificação virou mercado, há um mercado de certificação externa”.

O Banco B, por também ser um dos maiores bancos do país, também tem sido consultado pelo BACEN quando de suas dinâmicas de educação corporativa. Possui uma universidade corporativa institucionalizada nos termos de Eboli (2004), sendo que à época da pesquisa envolvia cerca de 242 pessoas na área de treinamento, possuía mais de 2 mil soluções de aprendizagem, seu corpo de trabalhadores em 2013 passava por uma média de 100 horas de treinamento anualmente, com aproximadamente 20 participações em iniciativas de educação corporativa por bancário ao longo do ano.

Os resultados internos comprovam que nas agências em que houve treinamento o desempenho foi melhor, reforçando a perspectiva de gestão por competências e aumento da competitividade no processo (Entrevistado 9). O Banco B também disponibiliza cursos online para clientes e a população em geral. Pesquisas de clima interno conduzidas pela área de gestão de pessoas indicavam, segundo o Entrevistado 9 que “66\% de respostas dizendo que os funcionários ficavam no banco porque têm oportunidade de treinamento”. Um processo que impulsionava a educação corporativa na organização estudada é que "normalmente quando o profissional entra no banco ele ainda é estudante na faculdade (...). O treinamento no banco completa a formação dele” (Entrevistado 9). A empresa, que teve “'turnover'” de 6,7\% em 2012, aposta no treinamento contínuo para ter sempre profissionais preparados para assumir os cargos de gerência e facilitar qualquer transição na carreira.

Por outro lado, ações estratégicas da universidade corporativa do Banco B foram relatadas como a realização periódica de diagnóstico com altos executivos, discussão com consultores para checar a concepção da educação corporativa com e para especialistas; articulação voltada para a mobilização de vários parceiros com abrangência nacional; o devido alinhamento ao modelo de competências da organização e o acompanhamento voltado para sustentar a perpetuidade do Banco $\mathrm{B}$, além de plataforma tecnológica própria de ensino à distancia, inclusive com a utilização de satélite, corroborando os achados de Eboli (2004).

Cabe ressaltar ainda que segundo o Entrevistado 9, o Banco B é um "banco de carreira. No ano passado [2012] abriram 1000 novas agências. Todos os 1000 novos gerentes foram captados e treinados/formados internamente”. Reforçou que "não existe uma faculdade de bancários”, a universidade corporativa incentiva o desenvolvimento das competências individuais voltadas para os objetivos do Banco B.

REAd | Porto Alegre - Edição 82 - N 3 - setembro/dezembro 2015 - p. 622-647 


\section{BANCÁRIA: DISTINTOS ATORES E PERSPECTIVAS}

O Banco C também apresenta uma estrutura de universidade corporativa, cuja "visão: um time talentoso, com brilho nos olhos e sonho grande” é disseminada por meio de três áreas: “corporativo e certificação"; "liderança e valores” e “centro de negócios”. A universidade corporativa tem como propósito “desenvolver pessoas, inovar, construir e implantar soluções de aprendizados”. A Entrevistada 10 ressaltou que por meio de programas de educação corporativa, o Banco C oferece formação, capacitação e desenvolvimento para os empregados, vinculadas às competências estratégicas, e alinhadas aos seus valores e cultura.

A Entrevistada 10 destacou ainda que um dos instrumentos de disseminação do conhecimento envolve os chamados "Projetos Transversais", voltados para vertentes como “inovação"; "mensuração de resultados"; e "gestão de conhecimento" tendo como suporte um “laboratório de projeto”. Há um grande envolvimento da área de gestão de pessoas nos processos de educação à distância, com suporte logístico e de infraestrutura. Os eixos de conhecimento trabalhados envolvem "negócios, excelência de pessoal, funcional e pessoas”. Em termos de infraestrutura utilizam "mais de 10 mídias diferentes. Saíram de uma abordagem lúdica para outra mais andragógica”. Afirmou que “os focos da Educação Corporativa são a disseminação de cultura; desenvolvimento de liderança; formação essencial e obrigatória legal; gestão orçamentária e gestão de indicadores (processo e qualidade)”.

Ao ser questionada quanto ao papel das competências no contexto da educação corporativa no Banco C, a Entrevistada 10 surpreendeu ao indicar que "competências é algo para o futuro”, uma vez que conhecimento é algo mais fácil de lidar no dia a dia sendo que a ferramenta de "treinamento normalmente é boa solução". Uma dificuldade que estão buscando superar é “como lidar com deficiência de formação básica e/ou mesmo de ensino superior”. Isto porque a “universidade corporativa precisa entender qual é situação do sujeito que chega ao banco para trabalhar e encaminhá-lo de acordo com o que o banco precisa”, porém, é necessário dar mais “atenção aos jovens: possuem pouca paciência para aprender”, sendo uma dificuldade para a gestão de pessoas no campo educacional e geracional.

A pesquisa revelou que Resolução BACEN 3.158, de dezembro de 2003 (BACEN, 2003) também desencadeou um movimento dos sindicatos bancários para oferecer cursos preparatórios aos exames e também reivindicar a concessão de dias de folga para provas de certificação; ou garantir tempo para o estudo para certificações dentro do horário de expediente. Com exceção destes aspectos, é possível afirmar-se que o ator sindical é praticamente ausente dos principais aspectos relacionados à negociação em torno da

REAd | Porto Alegre - Edição 82 - N 3 - setembro/dezembro 2015 - p. 622-647 
Wilson Aparecido Costa de Amorim, Marcus Vinicius Gonçalves da Cruz, Amyra Moyzes

Sarsur \& André Luiz Fischer

certificação bancária. As entrevistas apontam nesta direção, corroborando os achados de Cruz et al. (2012) de que o sindicato visa “...principalmente na questão da remuneração e eventualmente na questão do assédio moral”, uma vez que "competências não têm espaço no discurso sindical” (Grupo de Foco).

Segundo os sindicalistas, os cursos preparatórios para a certificação são uma tentativa de atração de associados por meio de serviços prestados e não chegam a resultar em acúmulo de conhecimento ou debate político no meio sindical. No levantamento documental junto às pautas de reivindicação dos bancários não há, por exemplo, reivindicações claras contra abusos dos bancos na exigência de certificação de seus empregados ou intenção de participação na definição dos conteúdos dos exames de certificação. Consequentemente, também não há cláusulas relacionadas ao assunto dentro da convenção coletiva.

No entanto, da parte dos bancos há nas práticas de gestão de pessoas forte indução à certificação dos trabalhadores bancários por meio da disponibilização das ferramentas de educação corporativa. Esta indução, conforme sindicalistas, não raro se dá por meio de pressão direta ou ameaça de perda de cargo ou oportunidade de promoção na carreira. A base para esta situação é dada pelo Entrevistado 4 (BACEN): os próprios bancos definem livremente quem deverá ter certificado como um requisito indispensável para ocupação de cargos, “...ninguém é mais promovido ou é contratado se não tiver a certificação”, daí os processos de treinamento e capacitação abordando conteúdos voltados para a certificação. A dimensão desta pressão pode ser encontrada nas estatísticas disponíveis. Nos últimos dez anos houve cerca de 620 mil trabalhadores inscritos nos exames, e em média apenas 55\% conseguiram aprovação. De outra forma, 35\% são reprovados gerando situações individuais profissionalmente desconfortáveis em termos de bloqueio à carreira ou manutenção do emprego, como frisaram os sindicalistas participantes do grupo de foco.

\section{CONSIDERAÇÕES FINAIS}

A dinâmica da atividade bancária ainda tem nas pessoas uma fonte significativa de vantagem comparativa e isto afeta a rotina organizacional e o conteúdo de suas tarefas. Tal circunstância exige um volume expressivo de recursos em torno das práticas e políticas de gestão de pessoas, destacando-se as iniciativas de educação corporativa que alinhadas às

REAd | Porto Alegre - Edição 82 - N 3 - setembro/dezembro 2015 - p. 622-647 


\section{BANCÁRIA: DISTINTOS ATORES E PERSPECTIVAS}

estratégias das instituições financeiras, delineiam sua atuação no mercado. A institucionalização dos processos de certificação dos trabalhadores torna-se um fenômeno que passa a ser incorporado nos seus parâmetros de qualificação. Verifica-se que não há uma linearidade nas apropriações das contribuições dos participantes da pesquisa, que especialmente por estarem em perspectivas e posições distintas e complementares, revelam suas contradições, conflitos e divergências em torno do tema.

Assim, as práticas de educação corporativa absorvem a dimensão dos processos de preparação de seus empregados para a certificação, ainda que não de forma exclusiva pelas instituições financeiras, uma vez que vão consolidando outras iniciativas nesse campo organizacional. Curiosamente, a institucionalização de entidades certificadoras resulta de uma negociação entre os bancos, suas entidades de representação e o BACEN. Os sindicatos de trabalhadores não participam desta negociação e se associam à certificação passivamente pela oferta de cursos preparatórios aos exames. Essa expansão sugere o início de uma cultura de certificação sob a justificativa de melhor atendimento ao cliente e preparação do bancário no bojo da expansão da bancarização no país.

A arena dos principais atores do sistema financeiro desenvolveu os processos de certificação, com uma participação desequilibrada entre os mesmos, mas que continua a expandir essa atividade e a aprimorar esse negócio, como ressaltou um dos entrevistados. A entrada de players poderosos como a FEBRABAN na dinâmica de treinamento é um sinal dessa expansão. Por sua vez, os bancos vêm aprimorando seus processos de internalização da certificação em suas práticas de gestão de pessoas por meio das iniciativas de educação corporativa. A dinâmica desta ação é diversificada, como atesta a breve análise nos bancos pesquisados, mas cada vez mais se particulariza culturalmente, reforçando uma das finalidades declaradas da educação corporativa de formação de sua força de trabalho segundo os valores do banco, a partir de discursos de valorização da instituição financeira e suas estratégias como "brilho nos olhos”, "banco de pessoas”, “certifique-se ou fique estagnado”.

Por sua vez, verifica-se que as iniciativas de educação corporativa ainda são muito tímidas em interagir com a educação formal voltada para melhoria de sua própria mão de obra. Assim, enquanto a certificação tornou-se indispensável para o emprego e carreira do bancário, o seu conteúdo e a forma para sua obtenção não estão em discussão: a certificação é uma imposição ao bancário e ele a busca como forma de ampliar sua empregabilidade.

REAd | Porto Alegre - Edição 82 - N 3 - setembro/dezembro 2015 - p. 622-647 
Wilson Aparecido Costa de Amorim, Marcus Vinicius Gonçalves da Cruz, Amyra Moyzes Sarsur \& André Luiz Fischer

Ainda não há estudos consistentes para verificar os impactos da certificação bancária na melhoria do serviço ao cliente e mesmo à economia do país, uma vez que se toma como certo esta necessidade a partir da ótica do órgão regulador e das instituições do setor, pela melhoria do conhecimento sobre o fazer do empregado do setor bancário, ainda que sem qualquer participação do sindicato dos trabalhadores. Daí o risco de se estabelecer um viés corporativo da certificação e regulação em que as suas vantagens atendam mais aos interesses das instituições do sistema financeiro, sob a égide legítima da educação corporativa, em detrimento do cliente, do trabalhador bancário e da própria sociedade.

\section{REFERÊNCIAS}

ANBIMA. Associação Brasileira das Entidades do Mercado Financeiro e Capitais. Sumário estatístico. São Paulo: ANBIMA, 2014.

AUSTIN, J. E. The collaboration challenge. San Francisco: Jossey-Bass Publishers, 2004.

BACEN. Banco Central do Brasil. Resolução 3.057, de 19/12/2002. Brasília: BACEN, 2002.

BACEN. Banco Central do Brasil. Resolução 3.158, de 17/12/2003. Brasília: BACEN, 2003.

BACEN. Banco Central do Brasil. Resolução 3.309, de 31/08/2005. Brasília: BACEN, 2005.

BACEN. Banco Central do Brasil. Resolução 3.954, de 24/02/2011. Brasília: BACEN, 2011.

BACEN. Banco Central do Brasil. Resolução 3.959, de 31/03/2011. Brasília: BACEN, 2011.

BACEN. Banco Central do Brasil. Relatório de evolução do Sistema Financeiro Nacional. Brasília: BACEN, 2013.

BARBOSA, A.C.; BITENCOURT, C.C.. Gestão de Competências: articulando indivíduos, organização e sociedade. In: BITENCOURT, C. et al.. Gestão contemporânea de pessoas: novas práticas, conceitos tradicionais. Porto Alegre: Bookman, 2010.

BORGES-ANDRADE, J.; ABBAD, G.; MOURÃO, L.. Treinamento, desenvolvimento e educação em organizações e trabalho. Porto Alegre: Artmed, 2006.

REAd | Porto Alegre - Edição 82 - N 3 - setembro/dezembro 2015 - p. 622-647 
CERQUEIRA, H.E.A.G.; AMORIM, W.A.C.. Evolução e características do emprego no setor bancário. In CARLEIAL, L.; VALLE, R. (Orgs). Reestruturação produtiva e mercado de trabalho no Brasil. São Paulo: HUCITEC-ABET, 1997.

COLLIS, J., HUSSEY, R. Pesquisa em Administração. Porto Alegre: Bookman, 2005.

CRESWELL, J.W.. Projeto de pesquisa. Porto Alegre: Artmed, 2010.

CRUZ, D. Educação corporativa: a proposta empresarial no discurso e na prática. Educação Revista, Belo Horizonte, v.26, n.2, p. 317-357, ago. 2010.

CRUZ, M. V. G.; SARSUR, A.S; AMORIM, W. A. C. Gestão de Competências nas Relações de Trabalho: o que pensam os sindicalistas? Revista de Administração Contemporânea (RAC), v.16, n.5, p.705-722, out. 2012.

DIEESE. Pesquisa de emprego bancário. São Paulo, nº 15, dez. 2012.

EBOLI, M. Educação corporativa no Brasil. São Paulo: Editora Gente, 2004.

EBOLI, M. P. Educação corporativa e desenvolvimento de competências. In: DUTRA, J. S.; FLEURY, M.; RUAS, R. (Org.) Competências. São Paulo: Atlas, 2008.

EBOLI, M.; FISCHER, A.; MORAES, F.; AMORIM, W. (Org.). Educação corporativa: fundamentos, evolução e implantação de projetos. São Paulo: Atlas, 2010.

FEBRABAN. Bancarização e inclusão financeira no Brasil. São Paulo: Febraban, 2011.

FLICK, U. Uma introdução à pesquisa qualitativa. Porto Alegre: Bookman, 2004.

GALVÃO, C. B. Fusões e aquisições. In MARQUES, R. M.; FERREIRA, M. R. J. (Orgs). O Brasil sob a nova ordem. São Paulo: Editora Saraiva, 2010. 
Wilson Aparecido Costa de Amorim, Marcus Vinicius Gonçalves da Cruz, Amyra Moyzes Sarsur \& André Luiz Fischer

GÓES, A. O. S.; SOUZA, M. E. A. A transformação da prática do bancário e a exigência de múltiplas competências. Revista de Administração Contemporânea - Eletrônica (RACEletrônica), v.2, n. 1, art. 8, p. 123-140, jan./abr., 2008.

HOURNEAUX JUNIOR, F.; EBOLI, M. P.; MARTINS, E. C. Educação corporativa e o papel do Chief Learning Officer. Revista Brasileira de Gestão de Negócios, São Paulo, v.10, n.22, p. 105-117, 2008.

LAVILLE, C. A construção do saber: manual da pesquisa em ciências humanas. Porto Alegre: Editora Artes Médicas Sul Ltda; Belo Horizonte: Editora UFMG, 1999.

LANVIN, B.; EVANS, P. (Ed.). The global talent competitive index 2013. Singapore: INSEAD, 2013.

MEISTER, J. C. Educação corporativa. São Paulo: Makron Books, 1999.

MINELLA, A. C. Maiores bancos privados no Brasil: um perfil econômico e sociopolítico. Sociologias, Porto Alegre, ano 9, n. 18, jul./dez. 2007.

MORAES, C. S. V.; LOPES NETO, S. Educação, formação profissional e certificação de conhecimentos. Educação \& Sociedade, Campinas, v.26, n.93, p.1435-1469, dez. 2005.

PEAK, M. H.. “Go corporate university”. Management Review, v.86, n.2, p.33-35, feb. 1997.

PRATES, D. M. Bancos e ciclo de crédito: da estabilização à crise financeira. In: MARCOLINO, L. C.; CARNEIRO, R. (Org.) Sistema financeiro e desenvolvimento no Brasil: do Plano Real à crise financeira. São Paulo: Publisher Brasil e Editora Gráfica Atitude Ltda., 2010.

REIS, G. G.; SILVA, L. M. T.; EBOLI, M. P. A prática reflexiva e suas contribuições para a educação corporativa. Revista de Gestão (REGE), São Paulo, v.17, n.4, p.403-419, out./dez., 2010.

SARSUR, A.M.. Empresabilidade como uma nova gestão de recursos humanos. In: BITENCOURT, C. (Org.). Gestão contemporânea de pessoas. Porto Alegre: Bookman, 2010. 